\section{A EDUCAÇÃO FÍSICA NO ENSINO MÉDIO E OS EXAMES ESTANDARDIZADOS: UMA ANÁLISE DAS QUESTÕES DO ENEM}

\author{
PHYSICAL EDUCATION IN HIGH SCHOOL AND STANDARDIZED \\ EXAMINATION: AN ANALYSIS OF THE ENEM QUESTIONS C
}

LA EDUCACIÓN FÍSICA EN LA ENSEÑANZA SECUNDARIA Y LOS

EXÁMENES ESTANDARIZADOS: UN ANÁLISIS DE LAS PREGUNTAS

DEL ENEM C P

doi' https://doi.org/10.22456/1982-8918.113585

(iD Rodrigo Marques* <rodrigo30mar_@hotmail.com>

Jean Carlos Freitas Gama** <jeanfreitas.gama@gmail.com>

Geraldo Luzia Oliveira Junior** <juninho01519986718@gmail.com>

Amarílio Ferreira Neto** <amariliovix@gmail.com>

Wagner dos Santos** <wagnercefd@gmail.com>

*Prefeitura Municipal de Vila Velha. Vila Velha, ES, Brasil.

**Universidade Federal do Espírito Santo. Vitória, ES, Brasil.

Resumo: O artigo analisa as questões do novo Enem que apresentam objetos de conhecimento da Educação Física, compreendendo as relações que se estabelecem por e entre as áreas do conhecimento mediadas pelas competências e habilidades. De natureza qualitativa, utiliza a análise crítico-documental como metodologia. As fontes são compostas por: 49 questões relacionadas com a Educação Física no exame (2009 a 2017), as Diretrizes Nacionais para o Ensino Médio, o Documento Básico do Enem e a Matriz de Referência do Enem. Os usos e apropriações dos objetos de conhecimento da Educação Física, devido à sua natureza multidisciplinar, favorecem a exigência da elaboração das questões do exame visando à interdisciplinaridade por e entre as áreas do conhecimento, explorando as relações cotidianas dos sujeitos. A interação entre os objetivos da área de Linguagens e suas Tecnologias, promovida pelo exame, permite-nos compreender a Educação Física dentro de um contexto amplo de formação, para além do saberes de domínio.

Palavras chave: Questões de prova. Educação Física. Ensino fundamental e médio. Pesquisa qualitativa.
Recebido em: 30 abr. 2021 Aprovado em: 18 nov. 2021 Publicado em: 28 dez. 2021

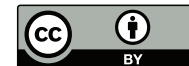

Este é um artigo publicado sob a licença Creative Commons Atribuição 4.0 Internacional (CC BY 4.0). elSSN: $1982-8918$ 


\section{INTRODUÇÃO}

Compreender a complexidade da avaliação de sistemas educacionais em países como o Brasil se mostra um desafio, sobretudo quando voltamos nossos olhares à Educação Física (EF) e suas singularidades. Os chamados exames estandardizados têm se mostrado um elemento fundamental para a elaboração de políticas públicas e ações estratégicas no cenário educacional (BELTRÃO, 2014; MARQUES; STIEG; SANTOS, 2020).

Cerón e Cruz (2013) evidenciam que, especificamente na América Latina, nas últimas duas décadas, países como o Chile e o Brasil têm criado sistemas nacionais para avaliar a qualidade da formação, o que resultou na instalação de vários mecanismos para medir os resultados dos exames estandardizados. Segundo os autores, esses países também estão submetidos a avaliações de sistemas internacionais, como: International Association for the Evaluation of Educational Achievement (IEA), Organização para Cooperação e Desenvolvimento Econômico (OCDE) e o Programme for International Student Assessment (Pisa).

No Brasil, conforme Sudbrack e Cocco (2014), os exames estandardizados se intensificaram na segunda metade da década de 1990, quando a qualidade da educação ganhou maior relevo, tornando-se um objeto de regulação pública federal. Dessa forma, as informações sobre as condições do ensino passaram a ser estruturadas a partir de um sistema nacional de avaliação.

O Ministério da Educação (MEC) tem promovido diversos exames estandardizados para a educação básica e para o ensino superior, que englobam diferentes programas, como: o Sistema de Avaliação da Educação Básica (Saeb), que foi consolidado na segunda metade da década de 1990; o Exame Nacional do Ensino Médio (Enem); o Exame Nacional para Certificação de Jovens e Adultos (Encceja); a Prova Brasil; a Provinha Brasil; e o Sistema Nacional de Avaliação da Educação Superior (Sinaes).

Dentre eles, destacamos o Enem, que é percebido como um sistema avaliativo complexo, com informações relevantes acerca do desempenho estudantil e dos contextos intra e extraescolares. Teoricamente, esses dados são utilizados para aprimorar as políticas educacionais rumo à universalização da qualidade do ensino como direito dos cidadãos (SILVA, 2010; SUDBRACK; COCCO, 2014; VIANNA, 2014).

Esse exame estandardizado tem como objetivo atuar na formulação de políticas educacionais em diferentes níveis. Segundo o Instituto Nacional de Estudos e Pesquisas Educacionais Anísio Teixeira (Inep), tal processo visa qualificar e classificar o nível educacional do ensino das escolas públicas e privadas do Brasil. Entretanto, é preciso estar atento e realizar uma análise crítica quanto a isso, uma vez que esse é um exame complexo e repleto de intencionalidades.

A partir do ano de 2009, as medidas governamentais estimularam o uso do Enem não apenas como um processo de avaliação do Ensino Médio, mas também como uma forma de os estudantes terem acesso ao Ensino Superior no Brasil, por meio de programas governamentais, como o Sistema de Seleção Unificada 
(Sisu) e o Programa Universidade para Todos (Prouni), que unificou a seleção para universidades públicas e viabilizou a entrada nas particulares (SILVEIRA; BARBOSA; SILVA, 2015).

O Enem foi instituído pela Portaria MEC n 438/1998 (BRASIL, 1998) como procedimento de avaliação do desempenho do aluno. O Decreto $n^{\circ} 5.493 / 2005$ (BRASIL, 2005), que regulamenta o Prouni, exigiu mudanças no exame a partir de 2004, dando início à sua segunda fase, quando começou a funcionar como processo seletivo do Estado, com a finalidade de conceder bolsas de estudo integrais e parciais em instituições de Ensino Superior privadas.

A fase denominada de "novo Enem" ocorreu com base na Portaria no 109, de 27 de maio de 2009 (BRASIL, 2009b). Nesse caso, notamos que, para além de selecionar e avaliar, o exame se transformou em um elemento político de "moeda de troca" entre as ações do governo e a abertura de novas vagas nas entidades particulares de Ensino Superior no país. Aqui fica evidenciado o crescimento exponencial dessas instituições, tanto em oferta de bolsas, quanto financeiramente (GOMES, 2017). Se, por um lado, o Enem serviu de instrumento a uma política afirmativa que visava combater a desigualdade de acesso ao Ensino Superior, por outro, evidenciou a criação de conglomerados educacionais e a mercantilização da entrada nessa etapa formativa.

Partindo de tais informações, estabelecemos como primeiro procedimento reunir os documentos orientadores do Enem: Diretrizes Nacionais para o Ensino Médio (DCENEM) (BRASIL, 1998); Orientações Educacionais Complementares aos Parâmetros Curriculares Nacionais (PCN+) (BRASIL, 2006); Documento Básico do Enem (BRASIL, 2002); e Matriz de Referência do Enem (BRASIL, 2009a), que servem de base para o novo Enem, com o objetivo de entender a fundamentação teórica, apropriação e os usos da disciplina EF no exame.

Nesse contexto, percebemos que a EF foi inserida na Competência de Área 3, que aponta, na matriz de referência do exame, que o aluno deve ser capaz de: "Compreender e usar a linguagem corporal como relevante para a própria vida, integradora social e formadora de identidade" (BRASIL, 2009a, p. 2). Evidenciamos que a organização geral da prova é feita por grandes áreas do conhecimento e cada uma apresenta suas competências específicas. Nesse caso, a EF está na Área de Linguagens e suas Tecnologias, a qual tem nove competências de área.

A partir dessas proposições, sobretudo da Competência de Área 3, as provas passaram a ter questões com as habilidades e competências referentes ao componente curricular EF, desenvolvidas no diálogo com outros integrantes da área, uma vez que a leitura estabelecida é sobre a área como um todo e não sobre uma disciplina específica.

Assim, questionamos: quais são os componentes curriculares que dialogam com a EF, visando estabelecer a interdisciplinaridade ${ }^{1}$ por e entre as áreas do

1 No diálogo com as Diretrizes Curriculares Nacionais para o Ensino Médio (DCNEMs), em linhas gerais, apontamos que a interdisciplinaridade se configura como o diálogo permanente que todo conhecimento mantém com outros conhecimentos de diferentes áreas, em uma abordagem teórico-metodológica de trabalho integrativo, aberto e dialogado. Assim, ela pressupõe a transferência de métodos de uma disciplina para outra (BRASIL, 2013). 
conhecimento? Quais são os objetos de conhecimento da EF mais utilizados nas questões dos exames?

Com isso, objetivamos, neste artigo, analisar as questões do novo Enem que apresentam objetos de conhecimento da EF, compreendendo as relações que se estabelecem por e entre as áreas do conhecimento mediadas pelas competências e habilidades. Dessa forma, captamos os usos e apropriações (CERTEAU, 2012), as relações com os saberes (CHARLOT, 2000) e os fundamentos que lhes oferecem suporte.

\section{METODOLOGIA}

Esta pesquisa é de caráter qualitativo (FLICK, 2004) e se ancora nos preceitos da crítica documental (BLOCH, 2001). As fontes são os documentos orientadores do Enem, bem como as provas do novo Enem aplicadas entre 2009 e 2017. Nesse caso, a periodização estabelecida neste trabalho justifica-se pelo fato de 2009 ser o ano de inserção da EF no novo Enem e 2017 por ser o último exame aplicado no período em que realizamos a imersão, classificação e categorização das fontes.

Segundo Bloch (2001), as fontes desse modelo de pesquisa são os testemunhos históricos. A sua diversidade é quase infinita, pois são constituídas basicamente por tudo o que o homem escreve, diz, fabrica, toca, tudo o que deve e pode trazer informação sobre ele.

Estamos, a esse respeito, na situação do investigador que se esforça para reconstruir um crime ao qual não assistiu; do físico, que, retido no quarto pela gripe, só conhecesse os resultados de suas experiências graças aos relatórios de um funcionário de laboratório. Em suma, em contraste com o conhecimento do presente, o do passado seria necessariamente 'indireto' (BLOCH, 2001, p. 69).

Dessa maneira, a observação e a análise crítica dos documentos do Enem podem ser realizadas de forma indireta e subjetiva, no passado, e de forma direta, no presente. Bloch (2001) ainda evidencia a importância de que não se devem produzir afirmações sem que elas antes estejam na condição de serem verificadas. Para ele, a crítica documental consiste em questionar as fontes e fazê-las falar, tendo como principal eixo norteador a compreensão cultural dos acontecimentos.

Também dialogamos com a micro-história italiana, por meio de Carlo Ginzburg (2002) e o Paradigma Indiciário para estabelecer nosso referencial teóricometodológico. Para ele, a realidade deve ser percebida partindo dos aspectos micro e investigando o que está na periferia. Assim, demonstra que, ao fazermos uma análise dos fatos, precisamos trabalhar com a ideia de verossimilhança ${ }^{2} \mathrm{e}, \operatorname{logo}$, permanecer sempre atentos aos pormenores, ao "não dito", ao não oficial, às probabilidades e possibilidades, pois o objeto se constitui como um grande tapete tecido por vários fios que se entrecruzam formando uma trama. Em um instrumento como o Enem, esse movimento não é diferente. "A análise micro-histórica é, portanto, bifronte. Por um lado, movendo-se numa escala reduzida [...]. Por outro lado, propõe-se indagar as

2 Conforme Ginzburg (2002), o verossímil é aquilo que parece verdadeiro por não contrariar a verdade, é aquilo que é possível ou provável. 
estruturas invisíveis dentro das quais aquele vivido se articula" (GINZBURG, 1989, p.177-178).

Em nosso caso, tanto a crítica documental (BLOCH, 2001) como a microhistória (GINZBURG, 1989, 2002) são fundamentais, pois nos auxiliam a compreender o Enem não apenas como uma prova, mas também como uma ferramenta cultural ampla, intencional e estratégica, constituída por quem está nos lugares de poder. Assim, torna-se importante fazer as perguntas certas às fontes e estabelecer, como fio condutor das análises, o diálogo entre esses autores, uma vez que ambos partem de uma perspectiva histórica e também cultural.

As interpretações e conhecimentos construídos sob um objeto como esse se caracterizam por meio das ações humanas no tempo e se constituem nos vestígios (documentos) deixados. Nesse sentido, é um conhecimento que está sempre se modificando no cotidiano.

Ao tratarmos o Enem com esse enfoque, estamos nos propondo, por meio da crítica documental, compreender as relações estabelecidas entre o macro (questões da prova e conteúdo geral), partindo das análises e entendimento dos contextos micro (habilidades e competências específicas da EF e seus diálogos interdisciplinares), para que possamos perceber a construção das relações estabelecidas e os desfechos ocorridos nesse exame estandardizado brasileiro. Dessa forma, a apreensão das singularidades, pistas, sinais e indícios nos ajuda a (re)construir uma realidade formando uma teia de significados para compreendermos a inserção e o papel da EF no Enem e, consequentemente, no próprio Ensino Médio.

O primeiro passo para a composição do banco de dados foi fazer o download em PDF das provas no site do Inep e separar aquelas relacionadas com a área de Linguagens e suas Tecnologias. Em seguida, realizamos a leitura na íntegra de cada enunciado, o que nos possibilitou mapear 49 questões referentes ao componente curricular EF.

Isso nos permitiu, ainda, identificar duas formas distintas no uso dos objetos de conhecimento da disciplina EF nas nove edições do novo Enem (2009-2017), a saber: a) como fim, compreendido como ato de utilizar a especificidade do componente curricular EF com o objetivo de alcançar as finalidades atribuídas às diferentes práticas corporais; e b) como meio, entendido como o ato de utilizar a especificidade (aspectos teóricos) do componente curricular EF como meio para se relacionar com e entre as áreas do conhecimento no exame. Ressaltamos que essa categorização também partiu da leitura e do diálogo inicial estabelecidos com os Documentos Orientadores do Enem, conforme apontado na introdução do estudo.

O segundo movimento foi submeter, por meio de um arquivo no bloco de notas, o corpus documental referente às questões ao software Interface de $R$ pour les Analyses Multidimensionnelles de Textes et de Questionnaires (Iramuteq). ${ }^{3}$ Com isso, foi gerada uma Classificação Hierárquica Descendente (Figura 1) e uma Nuvem de Palavras (Figura 2), elementos que nos serviram de auxílio nas análises.

3 Programa que realiza análises estatísticas com variáveis qualitativas de textos que possuem um campo léxico básico. Ele trabalha tanto com análises mais simplificadas, com o cálculo de frequência das palavras, até operações analíticas multivariadas, como a classificação hierárquica descendente e análise de similitude. A apresentação dos dados pode ser feita por meio de nuvem de palavras (CAMARGO; JUSTO, 2013). 
Evidenciamos a importância em utilizar cada vez mais esse tipo de software nas análises em pesquisas dessa natureza, sobretudo na área da EF, na qual trabalhos de abordagem qualitativa que utilizam essa ferramenta ainda são escassos. Conforme destacam Mello et al. (2018) e Paula et al. (2020), o Iramuteq é importante pois refina os dados de matriz textuais e lhes dá sua devida amplitude.

Ao nos fornecer diferentes formas de classificação/categorização, esse recurso nos permite trabalhar com os pormenores de um corpus documental amplo como o nosso (49 questões), sem perder suas características principais e mais gerais.

Com isso, é possível analisar e comparar elementos que passariam despercebidos apenas com a leitura na íntegra das provas e questões. Entretanto, ainda em relação ao software, "[...] o usuário deve ter em mente que a análise automática apresenta resultados genéricos que indicam caminhos a serem explorados e interpretados manualmente" (SALVIATI, 2017, p. 5).

Entendemos, assim, que, com o corpus documental submetido ao Iramuteq, é possível compreender as continuidades, descontinuidades e projeções para a produção do exame que é utilizado como processo seletivo para o acesso às vagas do ensino superior no sistema educacional brasileiro. Com o objetivo de compreender as semelhanças e diferenças apresentadas nos dois grupos de questões, a comparação atenta e instituída entre os fatos permite-nos discernir as influências exercidas uns sobre os outros.

Quanto às fontes, não nos interessou julgá-las, mas interrogá-las, entendendoas como artefatos culturalmente construídos e repletos de intencionalidades (BLOCH, 2001). Assim, ao explorarmos os documentos, analisamos os vestígios e os indícios deixados nas pistas (GINZBURG, 1989, 2002) de produção e materialização desse que é o maior e mais importante exame estandardizado da educação básica brasileira.

\section{CLASSIFICAÇÃO HIERÁRQUICA DESCENDENTE DOS TERMOS PRESENTES NAS QUESTÕES DE EF NO NOVO ENEM}

A Figura 1 apresenta a Classificação Hierárquica Descendente (CHD) dos termos mais frequentes nos corpora textuais analisados. Nessa organização, os segmentos de texto são correlacionados, formando uma representação ordenada de classe de palavras e vocábulos que são agrupados e ramificados segundo as divergências e aproximações temáticas entre as classes identificadas. Em nosso caso, o conteúdo analisado gerou cinco classes de palavras, denominadas de clusters, que são derivadas de duas ramificações iniciais. ${ }^{4}$

Ressaltamos que os clusters expõem gráfica e quantitativamente a disposição e a ordem dos termos, cabendo ao software apenas gerenciar as informações (SALVIATI, 2017). Nesse sentido, a todo momento recuperamos as questões e nos voltamos a elas na maneira original, já que a função de as interpretar criticamente

4 Conforme dados extraídos da ferramenta "estatísticas" do Iramuteq, o volume de informações submetidas produziu um total de 137 segmentos de texto com aproveitamento de 71,53\% (98). Emergiram 5.169 ocorrências (palavras, formas ou vocábulos): 1.963 formas distintas, 1.672 com apenas uma ocorrência (hapax) e um total de 1.534 formas ativas com frequência maior ou igual a três. O conteúdo analisado gerou cinco classes de palavras (clusters) que são derivadas de duas ramificações iniciais, conforme a Figura 1. 
cabe ao pesquisador.

A primeira ramificação isola a classe 5 em um bloco e subdivide outro com as classes 3 e 2 . A segunda ramificação é composta por dois ramos, um com a classe 4 e outro com a 1. A função semântica expressa em cada ramo da Figura 1 se distancia a cada subdivisão que sofre e à medida que "desce na árvore da hierarquia de palavras.

Figura 1 - Classificação hierárquica descendente: terminologias utilizadas nas questões com objetos de conhecimento da Educação Física no novo Enem

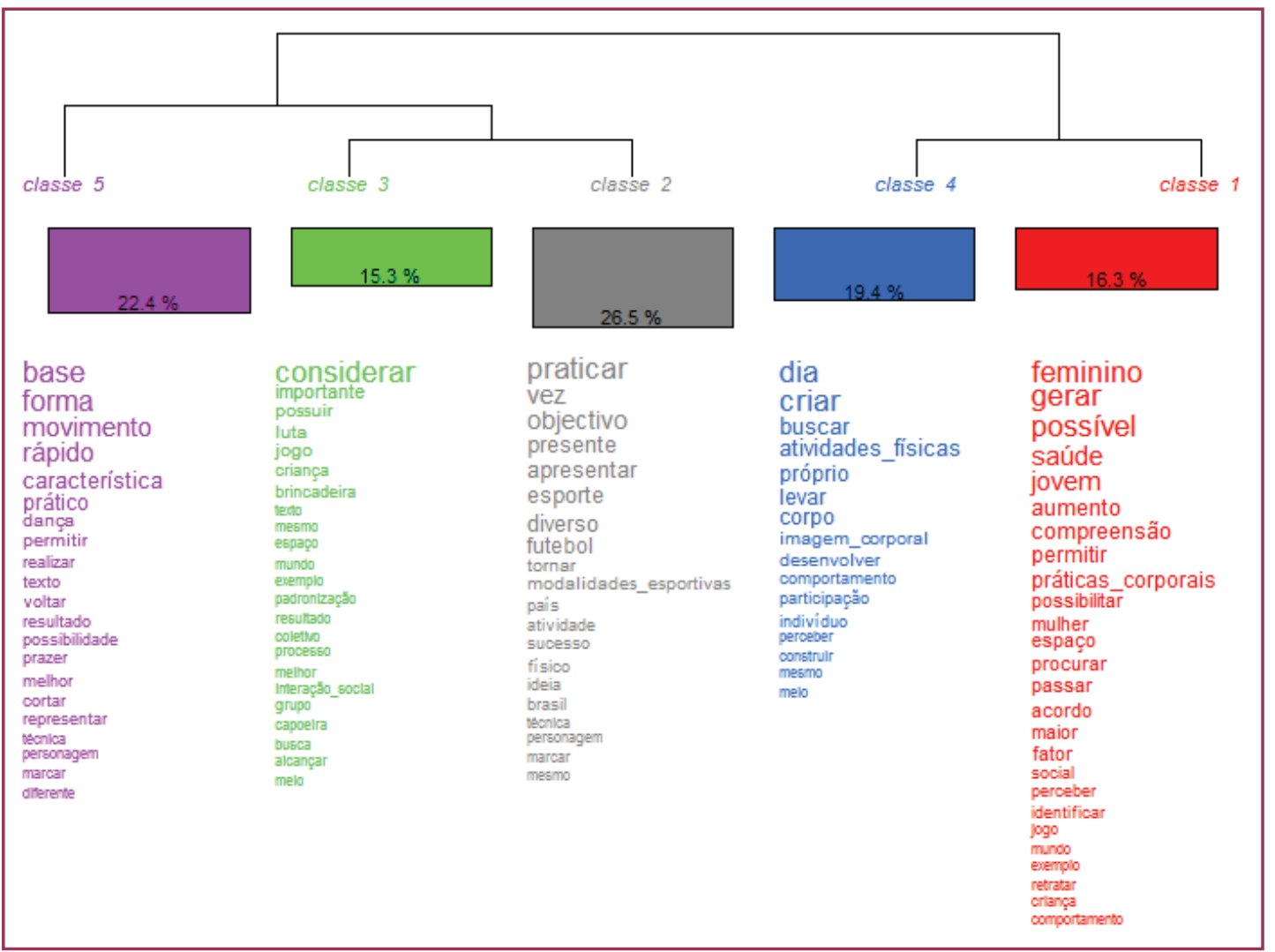

Fonte: Dados da pesquisa.

A classe 5 reúne $22,4 \%$ dos segmentos de texto considerados pelo Iramuteq para serem analisados. Nessa classe, estão representadas as palavras que formam um cluster de ramificação não subdividido. A análise indica-nos a presença da palavra "dança", que, no delineamento do estudo, se apresenta como uma das categorias, juntamente com os termos esporte, saúde, lutas, jogos e brincadeiras, que servem de base para indicar os objetos de conhecimento da EF que serão utilizados na composição das questões do exame.

Ressaltamos que a categoria dança contribuiu com oito questões no novo Enem. Ao revisarmos essas questões, percebemos que elas contemplam as palavras em destaque por ordem na classe 5 (base, formas, movimento, rápido, característica e prático). Nesse sentido, evidenciamos que a dança sofre as influências das rápidas mudanças culturais derivando em diversas manifestações rítmicas (forró, maxixe, xote e frevo). Essas influências servem de base para as transformações que, com o passar do tempo, dão origem a diferentes ritmos, que têm como características movimentos próprios delineados pela prática (Questão 108, 2010). 
As palavras com menor destaque na classe 5 caracterizam os usos e apropriações que são efetivadas por meio da prática da dança, que pode ser realizada com o intuito de obter o aprendizado dos movimentos técnicos, pelo prazer, visando a resultados relacionados com a estética corporal (emagrecimento), além de apresentar diferentes modalidades e não ser restrita a um determinado grupo social. Nesse sentido, seus usos estão associados a integração, socialização, divertimento e respeito aos costumes e tradições (Questão 107, 2014).

Quando as questões de dança abordam aspectos ligados a movimentos técnicos, ritmo e resultado, elas estabelecem relação com os usos que são feitos dos conteúdos do componente curricular EF, voltados para o rendimento (esporte competitivo ou profissional), diferenciando-se, assim, das diretrizes e bases que estabelecem o seu uso curricular na escola.

Nesse caso, a dança é compreendida como um conteúdo de manifestação artística que propicia a "[...] experimentação de diferentes improvisações e composições coreográficas, partindo de fontes diversas (orientações, jogos, elementos de movimento, sons e silêncio, histórias etc.)" (BRASIL, 2006, p. 194).

Essas considerações nos remetem à "disputa" existente entre os componentes curriculares EF e Artes sobre a dança. O cotidiano escolar, segundo Gonçalves (2017), é um espaço/tempo de negociações e de sentidos de (re)criação e (re)invenção dos saberes/fazeres, valores e emoções. Assim, não é neutro e nele coexistem vários fatores externos e internos que influenciam a maneira como os currículos são pensados/praticados e tecidos.

Ao tratar a dança como um conteúdo da EF, autores como Pellegrini (1988) indicam-nos que ela estabelece estreita relação com o movimento humano, seus aspectos históricos e socioculturais. Por outro lado, Strazzacappa (2014) evidencia que o componente curricular Arte tem como ementa uma linguagem visual, teatral e musical da dança para a aprendizagem. Para o autor, a dança vai além das repetições de passos. É o aprendizado de todo um contexto cultural.

Ainda evidenciamos que, na Matriz de Referência do Enem (BRASIL, 2009a), na qual se estabelecem as áreas do conhecimento, ambos os componentes fazem parte da área Linguagens e suas Tecnologias, tendo suas competências e habilidades próprias, porém interagem para realizar os aspectos inter e transdisciplinares exigidos pelo documento Fundamentação Teórica do Enem (2009a).

$\mathrm{Na}$ primeira ramificação, temos uma subdivisão dando origem à classe 3 , que reúne $15,3 \%$ dos segmentos de textos, e a classe 2 , com $26,5 \%$. A relação estabelecida entre esses clusters nos permite considerar que a aproximação das categorias esporte, lutas, jogos e brincadeiras acontece devido ao modo polimórfico e polissêmico com o qual elas são usadas e apropriadas nas questões do Enem, associando-se com rendimento, lazer, escola, esporte recreativo e participativo. Quando analisamos no exame as questões desses conteúdos, é possível relacionálas a termos como "o jogo de futebol", "o judô é um esporte olímpico", "futebol é uma prática de lazer" (Questão 132, 2016), o que nos revela os diferentes sentidos que Ihes são atribuídos (Questões 16, 2018; 97, 2014). 
Aclasse 2, em que o termo esporte está incluído, representa o maior percentual $(26,5 \%)$ dos segmentos de texto considerados. De igual modo, o número de questões no novo Enem que representa a categoria esporte tem maior relevância quantitativa, com 16 contribuições. As palavras em destaque nessa classe (praticar, objetivo, vez, presente, apresentar, diverso e futebol) são utilizadas nas questões do esporte na composição de termos que expressam os usos que são feitos do conteúdo.

Compreendemos que o esporte se constitui como um fenômeno, com inserção social ampla e que deve ter campos formativos específicos (GAMA; FERREIRA NETO; SANTOS, 2021). Quando utilizado na composição das questões do novo Enem, possibilitou o diálogo com o conhecimento social estabelecido historicamente entre os sujeitos, provocando a possibilidade de reflexões sobre as suas influências nas formações socioculturais do Brasil, demarcando a ideia, por exemplo, do "país do futebol". Nesse sentido, mesmo que a relação com o saber seja permeada por interações sociais, Charlot (2000, p. 68) nos adverte que "[...] não devemos confundir com uma mera posição social, já que a sociedade não é apenas um conjunto de posições, ela também é história".

Ao refletir sobre as influências nas formações socioculturais do Brasil, o homem comum age diante de uma "[...] produção racionalizada, expansionista, centralizada e barulhenta, produzindo um tipo diverso de consumo, que tem como característica a clandestinidade e a invisibilidade pela forma como usa aquilo que lhe é imposto" (CERTEAU, 2012, p. 45).

Nesse sentido, temos a indicação de que a prática do esporte, principalmente o futebol, com diferentes objetivos, tem se tornado cada vez mais presente no cotidiano dos sujeitos, favorecendo o pensamento reducionista do senso comum que associa a EF apenas às práticas esportivas e secundariza conteúdos, como a saúde, a dança, as lutas, a ginástica, os jogos e as brincadeiras.

$\mathrm{Na}$ classe 3, temos representadas as categorias lutas e jogos e brincadeiras que, juntas, contribuíram com dez questões no exame. A palavra em destaque nessa classe ("considerar") aparece nas questões que se reportam a lutas, justamente problematizando o que se compreende sobre essa prática em diferentes contextos sociais (Questão 108, 2011).

As lutas são abordadas para evidenciar, partindo do seu passado e dependendo do seu contexto, o seu caráter violento e marginalizado, além de discutir as questões de gênero (masculino e feminino) em sua prática. Contudo, indica que novas medidas estão sendo criadas, como a institucionalização de regras e espaços adequados para homens e mulheres, para que essas características pejorativas possam ser revertidas e a prática difundida (Questão 128, 2016).

Sobre o aspecto violento e marginalizado atribuído às lutas no ambiente escolar, So e Betti (2009) argumentam que a violência é um modo de expressão e comunicação dos alunos em reação a certas interações sociais. Em relação ao meio, ao estresse, à frustração, não pode ser totalmente eliminada ou subjugada pelos educadores.

Quando relacionamos o conteúdo lutas com as questões de gênero (masculino e feminino) do exame, entendemos que elas trazem implicações sobre aquilo que 
se ensina e o que se aprende nas aulas de EF. Assim, ao realizar o seu trabalho, o professor deve ficar atento para não reproduzir a ideia de que as lutas são práticas exclusivas do sexo masculino. Nesse sentido, reconhecer as lutas como uma prática corporal comum para ambos os sexos possibilita reconhecer que:

[...] a diversidade de universos culturais de alunos no âmbito de práticas docentes implica não só a conscientização acerca do peso dessas práticas no sucesso ou no fracasso destes alunos, mas também na importância de se trabalhar no sentido de mobilizar as expectativas positivas que promovam a aprendizagem de todos, independentemente de raça, classe social, sexo ou padrões culturais (CANEN, 2001, p. 222).

Consideramos que, devido à falta de espaço apropriado para brincar, a escola se torna o local privilegiado para que o resgate desses conteúdos seja sistematizado no currículo ou estimulado durante os intervalos recreativos. Também percebemos que os objetos de conhecimento relacionados com as lutas, jogos e brincadeiras, permitem que os sujeitos vivenciem o conhecimento social estabelecido historicamente.

No diálogo com Charlot (2000), é preciso compreender que, nesse caso, as especificidades da EF se mostram nas apropriações, sobretudo, nas figuras do aprender ${ }^{5}$ presentes nos saberes de domínio e nos saberes relacionais, inscritos e aprendidos no/com o corpo. Entretanto, destacamos que os saberes-objeto também fazem parte dos objetos de conhecimento e aprendizagens da EF, uma vez que o corpo é por nós compreendido como um corpo-sujeito, onde não há separação entre o físico e o intelecto (CHARLOT, 2000; SANTOS et al., 2020).

Na segunda ramificação se deriva a classe 4, com 19,4\% dos segmentos de texto, e a classe 1, com 16,3\%. No cluster classe 1, temos a presença da categoria saúde, que contribuiu com 15 questões no novo Enem. A classe 4 se destaca das demais por não apresentar palavra correspondente com as categorias analisadas nos estudos. No entanto, quando analisamos as questões de saúde, percebemos que elas são complementares, justificando sua ligação com a classe 1.

Nas palavras em destaque na classe 1, chama-nos a atenção os termos "feminino" e "jovens". Ao retomarmos as questões de saúde, percebemos que esses sujeitos são evidenciados como grupos carentes de políticas públicas que tenham como objetivo incentivar a realização de suas práticas corporais, visando combater práticas consideradas ilegais e até mesmo nocivas à saúde (dieta da moda e uso de medicamentos) (Questão 134, 2009).

Neste caso, temos a palavra "criar" no cluster 4 e "gerar" no cluster 1, apresentando o sentido de oportunizar e garantir para o sexo feminino o acesso à atividade física e de lazer sem restrição com relação ao sexo masculino (Questão $99,2011)$ e, concomitantemente, realizar campanhas informativas sobre os perigos das dietas radicais, dos padrões estéticos impostos pela mídia e da busca pelo corpo perfeito sob qualquer circunstância (Questão 114, 2014). Já para os jovens, devem-se buscar iniciativas que contribuam para o acúmulo cultural de vivências 
das práticas corporais e a compreensão do papel do corpo no mundo da produção (Questão 132, 2006).

As palavras de menor destaque nas classes 1 e 4 (desenvolver, identificar, permitir, possibilitar, procurar) reforçam a característica existente nas questões do exame de conectar os sujeitos com os problemas do cotidiano, nesse caso, com relação às informações veiculadas nas mídias (revistas, redes sociais, televisão, rádio) sobre a ideia de que existe uma imagem corporal idealizada que leva as pessoas a buscar alternativas prejudiciais para sua saúde (Questão 14, 2009).

Quando nos referimos aos jogos e brincadeiras, a palavra "considerar" se conecta com as de menor destaque (criança, espaço, interação social) para evidenciar e comparar problemas que vêm assolando a atualidade, como a falta de espaço para brincar e o mercado do lazer que não está ao alcance das camadas mais pobres da sociedade (Questão 29, 2017). As crianças não se relacionam socialmente, como no passado, devido à escassez de locais apropriados para que seja realizada a interação social intermediada pelos jogos e brincadeiras (Questão 35, 2009).

A ligação dos termos nas classes 1 e 4 na mesma ramificação para representar a categoria saúde, nas questões relacionadas com o novo Enem, demonstrou ser a mais complexa. Acreditamos que essa ligação possa ser justificada com base na análise dos conteúdos da saúde no novo Enem. Verificamos que 12 das 15 questões são utilizadas como meio para se alcançar os objetivos da EF.

Se compararmos com o esporte, por exemplo, a categoria que tem o maior número de questões no exame, das 16 , apenas três estão como meio para alcançar os objetivos do componente curricular. Salientamos que a classificação hierárquica descendente indica a presença de um núcleo de palavras que mantêm uma relação constante, enquanto outras têm relação somente dentro de sua própria classe.

Considerando que o Enem, como toda avaliação, também é um instrumento formativo, indagamos em que aluno quer se formar, ao dar visibilidade, nas questões, às diferentes práticas culturais. Embora estejamos falando de um instrumento cujo uso, por vezes, ressalta o nosso sistema educacional desigual, o conteúdo utilizado para compor as questões demonstra as diferenças regionais do Brasil.

Os fatos nos permitem compreender o Enem como uma avaliação que, teoricamente, deveria ser utilizada como instrumento formativo. No entanto, o exame acaba se tornando uma ferramenta estratégica e repleta de intencionalidades pelos sujeitos que estão em lugares de poder para guiar os rumos da educação brasileira no sentido de estabelecer um padrão de aluno que se quer formar e um próprio padrão de educação básica e superior.

Com isso, entender o conceito de estratégias nesse contexto torna-se fundamental, pois nos mostra que elas são concebidas "[...] como cálculo (ou manipulação) das relações de forças que se torna possível a partir do momento em que um sujeito de querer e poder (uma empresa, um exército, uma cidade, uma instituição científica) pode ser isolado" (CERTEAU, 2012, p. 99-100). Assim, os sujeitos que governam a educação no país e também o próprio exame se consolidam como estratégias que têm seus impactos nas políticas educacionais brasileiras. 
Essas considerações nos levam a refletir sobre os diferentes usos eapropriações das relações que podem ser estabelecidas entre os objetos de conhecimento do componente curricular EF nas questões do novo Enem. Sua natureza multidisciplinar (Educação, Saúde, Sociologia, Filosofia) favorece a exigência do exame que advoga para que as questões sejam elaboradas com base na interdisciplinaridade por e entre as áreas do conhecimento e explorem as relações cotidianas dos sujeitos.

\subsection{NUVEM DE PALAVRAS MAIS FREQUENTES NAS QUESTÕES REFERENTES AO COMPONENTE CURRICULAR EF NO NOVO ENEM}

Analisar a recorrência e os usos da EF nas questões do novo Enem permitiunos compreender as diferentes relações de interdisciplinaridade pelas áreas do conhecimento, seus componentes curriculares e, consequentemente, seus objetos de conhecimento.

Os diferentes usos atribuídos a esses objetos da EF propostos pelo novo Enem também nos levam a refletir sobre as seguintes questões: quais são os principais termos utilizados para representar o componente curricular no exame? Quais as intenções no emprego de determinadas terminologias? Que influências contribuem para evidenciar os termos em destaque? Dessa forma, elaboramos, por meio do Iramuteq, uma nuvem de palavras com as questões do nosso banco de dados, conforme exposto na Figura 2.

Figura 2 - Nuvem de palavras dos enunciados das questões referentes aos objetos de conhecimento da Educação Física no Enem

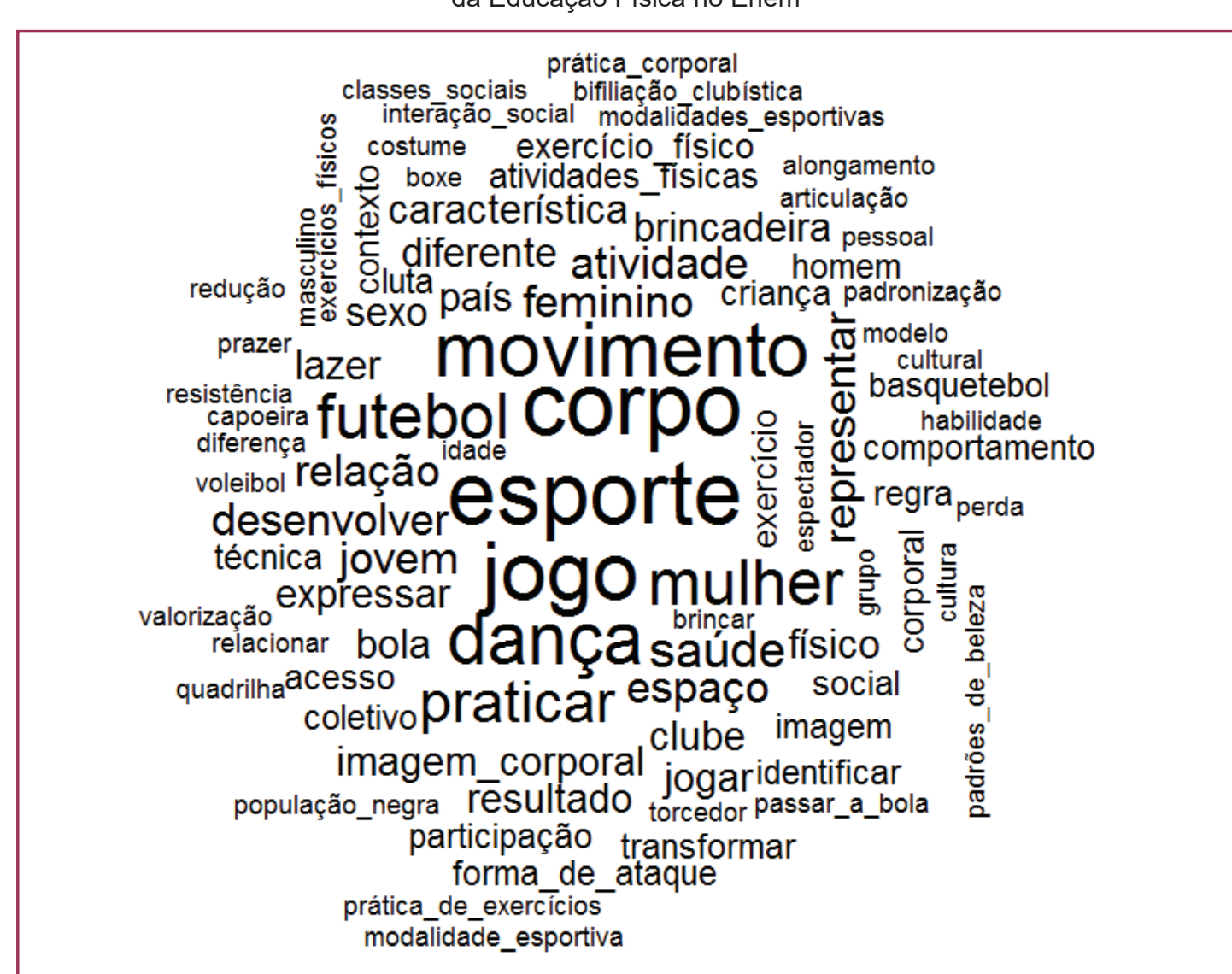


$\mathrm{Na}$ Figura 2, as palavras com maior recorrência se mostram maiores e centrais, já as periféricas são as que menos apareceram no corpus textual. Ressaltamos que a nuvem não expressa correlação entre as palavras, apenas a recorrência. Em nosso caso, a recorrência mínima para inclusão foi $\geq$ a três.

Uma primeira análise demonstra que esses termos representam os saberes que caracterizam a multidisciplinaridade da EF. Eles justificam, nas questões do novo Enem, o uso dos seus objetos de conhecimento como fim, com o objetivo de evidenciar as diferentes práticas corporais; e como meio, de maneira interdisciplinar por e entre as áreas do conhecimento. Nesse sentido, temos a área de Linguagens e suas Tecnologias dialogando com os componentes curriculares Português e Literatura, enfatizando o seguinte objetivo: estudos das práticas corporais com estudos do texto.

Quando a interdisciplinaridade é estabelecida entre as áreas do conhecimento, temos, por intermédio das questões, relação entre: Linguagens e suas Tecnologias (EF, Português, Literatura), Ciências Humanas (História e Sociologia) e Ciências da Natureza (Biologia) (Questões 115, 2012; 16, 2014; 124, 2015).

Gravitando no centro da Figura 2, temos as palavras: "esporte", "jogo" e "dança" representando as duas categorias, uso como fim e uso como meio. Assim, as palavras estão atendendo às exigências ao abordarem os objetivos da EF e os aspectos interdisciplinares, conforme determinado pelos documentos Matriz de Referência Enem (BRASIL, 2009a) e PCN+ (BRASIL, 2006), destacando-se com relação aos conteúdos saúde e lutas.

Ao evidenciar os objetivos da EF e os aspectos interdisciplinares, os objetos de conhecimento abordam, de acordo com Charlot (2000, p. 58), "[...] a prática dos saberes e os saberes das práticas". Conforme o autor, a prática do saber é, antes de tudo, uma prática que leva à resolução de problemas, à construção de conceitos, ou seja, a produzir efeitos de saber, construção de novos saberes a partir de saberes já adquiridos. Já o saber da prática refere-se ao conjunto de saberes disponibilizados pela prática, ou pelas pesquisas feitas sobre as práticas (CHARLOT, 2000).

Compreendemos as relações entre os saberes e por isso assinalamos o destaque de algumas categorias sobre as outras nos aspectos polimórficos e polissêmicos das palavras, além da utilização dos subconteúdos na formulação das questões. Por exemplo, quando a discussão sobre saúde tem relação com: a prevenção de doenças (obesidade, diabetes, bulimia, vigorexia e anorexia) (Questões: 114, 2014; 125, 2016); cuidados com o corpo por meio da alimentação, hábitos de vida considerados saudáveis ou não (Questão 103, 2009); prática de exercícios físicos e busca exagerada (doença) pelos padrões de estética corporal impostos socialmente (Questão134, 2009).

Isso também acontece com o conteúdo lutas, cujas questões enfatizam principalmente os subconteúdos: capoeira (Questão 109, 2014) e boxe (Questão 97, 2014), afastando a temática principal das palavras destacadas no centro.

Em específico, a nuvem nos apresentou oito palavras com recorrência elevada, o que nos permite agrupá-las em quatro grupos: a) esporte e futebol; b) corpo e mulher; c) jogo e dança; d) movimento e prática. 
No caso das palavras do grupo 1, a análise, com base nas questões do novo Enem, permite-nos considerar que o esporte representa a categoria com o maior número de questões, 17, das quais 14 são utilizadas como fim para alcançar os objetivos da EF. Nelas, o esporte apresenta diferentes usos, dependendo do objetivo que se pretende alcançar.

Dessa forma, temos seu uso associado a termos como: processo de desenvolvimento histórico-cultural do povo brasileiro (Questão 115, 2012); participação (Questão 31, 2017); performance, competição ou alto rendimento (Questão 100, 2011); produto de consumo, atividade física e meio de ascensão social (Questão 98, 2011). Essas características tornam o esporte um fenômeno plural e polissêmico por apresentar diversos significados para a sociedade.

As questões do Enem privilegiam o saber técnico, o fazer com as práticas corporais, representadas pelos esportes e, também, o processo concomitante de desenvolvimento sociocultural e esportivo do povo brasileiro. Esses objetos de conhecimento estão de acordo com a intervenção prática do professor e propiciam uma discussão crítica sobre a influência dos esportes na vida dos sujeitos, o que nos revela uma adequação com aquilo que deve ser ensinado e que está proposto no currículo para o Ensino Médio, fase em que os alunos realizam o exame.

Das 14 questões de esporte, a palavra futebol se apresenta em sete delas, cinco como temática principal (Questões: 21, 2002; 115, 2012; 16, 2014; 132, 2016; 19, 2017) e duas como complementação (Questões: 104, 2014; 31, 2017). No seu uso, é destacada a sua relação com a identidade do povo brasileiro, como podemos observar em fragmentos das questões em expressões como: "Aqui é o país do futebol" e "Brasil só é futebol” (Questão 115, 2012), "Alegria de ser brasileiro" (Questão 21, 2002) e "meio de interação social" (Questão 132, 2016).

Observamos que o esporte, mesmo sendo um conteúdo da EF que atende ao objetivo proposto pela Matriz de Referência do Enem (BRASIL, 2009a), estudos das práticas corporais, ao ser integrado na área de Linguagens e suas Tecnologias, passa a ser usado por outros componentes curriculares para realizar a interdisciplinaridade por e entre as áreas.

No grupo 2, temos a palavra "corpo" utilizada em três categorias (esporte, saúde e dança), mas, se levarmos em consideração suas derivações, como corporal, prática corporal e imagem corporal, conforme evidenciado na nuvem, podemos afirmar sua presença em todas as cinco categorias. Os usos da palavra corpo estabelecem relações com os aspectos biológicos (anatomia, funções, saúde, doença e nutrição) e sociológicos (cultural, feminino, estética corporal e padrão corporal).

Elas evidenciam a própria compreensão do campo, no qual uma corrente da EF acredita que seus objetivos devem ser propostos na Área das Ciências da Natureza e suas Tecnologias, estabelecendo um diálogo primário com a saúde, apresentando atividades físicas que visem promover a qualidade de vida e evitar as doenças (BAGRICHEVSKY; PALMA; ESTEVÃO, 2003; FARINATTI; FERREIRA, 2006); já a outra estabelece uma leitura a partir das Ciências Humanas e Sociais, viabilizando, 
também, uma discussão que relaciona a área com as implicações sociais, políticas e culturais (BETTI, 2009; MURAD, 2009).

A palavra "mulher" está presente em duas categorias, saúde e lutas. Nelas, são evidenciados os usos relacionados com os aspectos e as discussões de cunho social que têm como objetivo impor um padrão de estética corporal, principalmente influenciado pela mídia e pela indústria da beleza (Questão 26, 2017), além de questões de gênero ligadas ao preconceito sobre a participação da mulher em práticas corporais historicamente exclusivas para os homens, como é o caso das lutas (Questão 128, 2016).

No grupo 3, temos a palavra "jogo" presente em duas categorias, jogos e brincadeiras. Elas destacam seus usos como instrumento de interação social, sua participação voluntária, além do caráter lúdico que permite a participação de sujeitos de todas as idades e classes sociais, devido à simplicidade de suas regras e à possibilidade de sua vivência em espaços variados (Questão 97, 2013); e no esporte, por meio de expressões características ("começar o jogo" e "colocar a bola em jogo"), cujos sentidos nos remetem às situações relacionadas com a prática das diferentes modalidades (Questão 120, 2010). Aqui, as expressões das questões de esporte contribuíram para evidenciar a palavra "jogo", que não tem o mesmo sentido quando é relacionada com a categoria jogos e brincadeiras.

No grupo 4, temos as palavras "movimento" e "praticar" aparecendo nas categorias esporte e dança. Elas representam a finalidade, a especificidade e o fazer com a EF, ser capaz de dominar uma atividade ou um objeto (saber domínio), o aprendizado que não se obtém por meio de enunciados. Elas estão relacionadas com as ações cotidianas realizadas com o objetivo de alcançar benefícios físicos, por meio das práticas corporais e para caracterizar as diferentes modalidades e estilos de lutas e danças que são representativas da cultura corporal de movimento.

Assim, as análises possibilitam compreender que os objetos de conhecimento do componente curricular EF nas questões do exame contribuem com um contexto amplo de formação para além do saber domínio (fazer), promovendo, assim, a interação entre os saberes (CHARLOT, 2000). Ao mediar os seus conteúdos por e entre as áreas do conhecimento, a EF interage nas questões do Enem fundamentada nos seus processos históricos, culturais e sociológicos, estabelecendo relações com outros saberes e, portanto, com o mundo.

Fazendo uma retrospectiva quantitativa desses dados, constatamos que apenas $3,02 \%$ das questões do novo Enem trazem algum conteúdo relacionado com a EF, ou seja, apenas 49, em um universo de 1.620 , ao longo de nove edições. Isso demonstra que essa é uma disciplina que ainda precisa conquistar seu espaço na prova e se legitimar como objeto de conhecimento "fim", que tem suas especificidades e importância para a formação integral do sujeito. Nesse sentido, é preciso realizar um olhar crítico ao objeto e questionar como, quando e para que essas questões aparecem, além da ênfase que é dada ou não às especificidades da EF e também de que maneira o seu potencial interdisciplinar é explorado. 
Ainda percebemos que, das 49 questões analisadas, 24 abordam os objetos de conhecimento da EF como fim (compreendidos como ato de utilizar a especificidade da EF com o objetivo de alcançar as finalidades atribuídas às diferentes práticas corporais), o que corresponde a 48,9\%; já as outras 25 perguntas abordam os objetos de conhecimento da EF como meio, o que corresponde a 51,02\% (compreendida como ato de utilizar a especificidade da EF como meio para se relacionar com e entre as áreas do conhecimento e os componentes curriculares no exame). Esse é um panorama necessário, pois também nos ajuda a compreender a forma como as questões são elaboradas e como se relacionam com as habilidades e competências de determinadas áreas.

Embora tenhamos analisado as questões da EF vinculadas à área de linguagens, captamos o seu diálogo com objetos de conhecimento de outras áreas. A exemplo, mapeamos 15 questões que estão diretamente ligadas à temática saúde, abordadas em articulação com objetos de conhecimento das disciplinas Sociologia, Filosofia e Biologia. Esses dados evidenciam os desafios de se estabelecer, na prática pedagógica, o ensino dos objetos de conhecimento da EF em diálogo com as disciplinas escolares da área de conhecimento Linguagens e suas Tecnologias e entre as demais áreas.

Nossas análises corroboram as ideias de Santos et al. (2020) e enfatizam que a EF precisa se reafirmar no ambiente escolar por meio das identidades que são criadas para e por ela. Assim, a produção de sentidos sobre essa disciplina no Ensino Médio perpassa não só suas competências e habilidades, mas também a maneira como ela dialoga com as outras áreas e como se estabelece nessa relação, que não deve ser hierárquica, mas interdisciplinar em seu sentido amplo, dialogado e compartilhado.

\section{CONSIDERAÇÕES FINAIS}

Compreendemos que, no novo Enem, na área de Linguagens e suas Tecnologias, os objetivos produção e recepção de textos artísticos, estudos dos aspectos linguísticos e estudo argumentativo interagem com os estudos das práticas corporais, para que seus usos e apropriações possam ser materializados nas questões do exame, atendendo, assim, à necessidade de relacionar as competências e habilidades, conforme proposto na Matriz de Referência para o novo Enem (BRASIL, 2009a).

Ao interagir, mediado pelos objetivos da área de Linguagens e suas Tecnologias, o exame promove a interação entre os saberes (CHARLOT, 2000), permitindo compreender a EF dentro de um contexto mais amplo de formação.

No que se refere à interdisciplinaridade entre as áreas do conhecimento e seus componentes curriculares, identificamos os usos da EF dialogando com as Ciências Humanas e suas Tecnologias e as Ciências da Natureza e suas Tecnologias. $\mathrm{Na}$ primeira, mediada pela História e Sociologia, ressaltam-se os saberes socioculturais que possibilitam compreender os sujeitos de maneira ampliada, para além dos aspectos morfológicos e fisiológicos. Na segunda, a interação do componente 
curricular Biologia relaciona-se com o objetivo de estudos das práticas corporais, evidencia aspectos associados à saúde, à qualidade de vida (lazer, alimentação saudável, atividade física) e à prevenção de doenças (bulimia, obesidade e diabetes), considerando a incorporação dessas práticas ao cotidiano dos sujeitos.

Por fim, ressaltamos a contribuição do Iramuteq como ferramenta de auxílio para o processo de análise dos dados, permitindo-nos, com base nas questões de EF no novo Enem, compreender as apropriações e os usos das relações que se estabelecem entre os saberes, bem como a interdisciplinaridade por e entre as áreas do conhecimento.

Indicamos, ainda, a necessidade de estudos futuros que tenham como objetivo analisar a prática dos profissionais (pedagogos e professores), para compreendermos os procedimentos didático-pedagógicos que estão sendo adotados pelas redes de ensino, visando atender aos aspectos interdisciplinares por e entre as áreas do conhecimento, durante o processo de formação dos alunos para prestar o exame.

\section{REFERÊNCIAS}

BAGRICHEVSKY, Marcos; PALMA, Alexandre; ESTEVÃO, Adriana. A saúde em debate na Educação Física. Blumenau: Edibes, 2003.

BELTRÃO, José Arlen. A Educação Física na escola do vestibular: as possíveis implicações do ENEM. Movimento (Porto Alegre), v. 20, n. 2, p. 819-840, 2014. DOI: https://doi. org/10.22456/1982-8918.41801

BETTI, Mauro. Educação Física e sociedade: a Educação Física na escola brasileira. Ijuí, RS: Editora Unijuí, 2009.

BLOCH, Marc. Apologia da história ou o ofício de historiador. Rio de Janeiro, RJ: Zahar, 2001.

BRASIL. Orientações educacionais complementares aos parâmetros curriculares nacionais $(\mathrm{PCN}+)$ : linguagens, códigos e suas tecnologias. Diário Oficial da União, Brasília, DF, 2006. Disponível em: http://portal.mec.gov.br/seb/arquivos/pdf/linguagens02.pdf. Acesso em 08 jul. 2021.

BRASIL. Ministério da Educação. Portaria MEC n 438, de 28 de maio de 1998. Institui o Exame Nacional do Ensino Médio - ENEM. Diário Oficial da União, Brasília, DF, 1998. Disponível em: http://www.crmariocovas.sp.gov.br/pdf/diretrizes_p0178-0181_c.pdf. Acesso em: 20 nov. 2021.

BRASIL. Ministério da Educação. Conselho Nacional de Educação. Decreto ${ }^{\circ} 5.493$, de 18 de julho de 2005. Regulamenta o disposto na Lei no 11.096, de 13 de janeiro de 2005. Diário Oficial da União, Brasília, DF, 2005. Disponível em: http://www.planalto.gov.br/ ccivil_03/_ato2004-2006/2005/decreto/d5493.htm. Acesso em: 20 nov. 2021.

BRASIL. Ministério da Educação. Instituto Nacional de Estudos e Pesquisas Educacionais Anísio Teixeira Brasília. Documento Básico do Enem. Diário Oficial da União, Brasília, DF, 2002. Disponível em: https://download.inep.gov.br/publicacoes/institucionais/avaliacoes_e exames_da_educacao_basica/enem_exame_nacional_do_ensino_medio_documento_ basico_2002.pdf. Acesso em 8 jul. 2021. 
BRASIL. Ministério da Educação. Instituto Nacional de Estudos e Pesquisas Educacionais Anísio Teixeira. Matriz de Referência do Enem. Diário Oficial da União, Brasília, DF, 2009a. Disponível em: https://download.inep.gov.br/download/enem/matriz referencia.pdf. Acesso em: 25 ago. 2021.

BRASIL. Ministério da Educação. Instituto Nacional de Estudos e Pesquisas Educacionais Anísio Teixeira. Portaria $n^{\circ} 109$, de 27 de maio de 2009. Dispõe sobre alterações no Exame Nacional do Ensino Médio. Diário Oficial da União, Brasília, DF, 2009b. Disponível em: https://download.inep.gov.br/educacao basica/enem/legislacao/2009/portaria enem2009_\%203.pdf. Acesso em: 20 nov. 2021.

BRASIL. Ministério da Educação. Secretaria de Educação Básica. Diretrizes Curriculares Nacionais da Educação Básica. Diário Oficial da União, Brasília, DF, 2013. Disponível em: http://portal.mec.gov.br/index.php?option=com docman\&view=download\&alias=13448diretrizes-curiculares-nacionais-2013-pdf\&ltemid=30192. Acesso em: 20 jun. 2021.

CAMARGO, Brígido Vizeu; JUSTO, Ana Maria. Iramuteq: um software gratuito para análise de dados textuais. Temas em Psicologia, v. 21, n. 2, p. 513-518, 2013.

CANEN, Ana. Universos culturais e representações docentes: subsídios para a formação de professores para a diversidade cultural. Educação e Sociedade, v. 22, n. 77, p. 207-227, 2001.

CERÓN, Manuel Sánchez; CRUZ, Francisca Maríadel Sagrario Corte. Las evaluaciones estandarizadas: sus efectos en tres países latinoamericanos. Revista Latinoamericana de Estudios Educativos, v. 43, n. 1, p. 97-124, 2013.

CERTEAU, Michel. A invenção do cotidiano: artes de fazer. 15. ed. Petrópolis, RJ: Vozes, 2012.

CHARLOT, Bernard. Da relação com o saber: elementos para uma teoria. Porto Alegre: Artmed, 2000.

FARINATTI, Paulo de Tarso Veras; FERREIRA, Marcos Santos. Saúde, promoção da saúde e Educação Física. Rio de Janeiro: Ed. UERJ, 2006.

FLICK, Uwe. Uma introdução à pesquisa qualitativa. Porto Alegre: Bookman, 2004.

GAMA Jean Carlos Freitas; FERREIRA NETO, Amarílio; SANTOS, Wagner dos.

Formação para atuação com o esporte: características bibliométricas e redes de colaboração. Movimento (Porto Alegre), v. 27, p. e27017, jan./dez. 2021. DOI: https://doi. org/10.22456/1982-8918.109936

GINZBURG, Carlo. A micro-história e outros ensaios. Rio de Janeiro: Memória e sociedade, 1989.

GINZBURG, Carlo. Mitos, emblemas, sinais: Morfologia e história. 2. ed. São Paulo: Companhia das Letras, 2002.

GOMES, Lívia Letícia Zanier. O Novo ENEM em questionamento enquanto política focalizada de indução curricular e de democratização de acesso ao Ensino Superior. Saberes Interdisciplinares, v. 6, n. 12, p. 15-24, 2017.

GONÇALVES, Rafael Marques. Políticopráticas de currículo no/do cotidiano escolar. Revista de Estudo e Pesquisa em Educação, v. 19, n. 1, jan./jun. 2017. DOI: https://doi. org/10.34019/1984-5499.2017.v19.19012. 
MARQUES, Rodrigo; STIEG, Ronildo; SANTOS, Wagner dos. Exames estandardizados: análise dos modelos e das teorias na produção acadêmica. Revista Meta: Avaliação, v. 12, n. 34, p. 1-27, 2020.

MELLO, André da Silva et al. Representações sociais dos participantes de projeto esportivo de Vitória. Movimento (Porto Alegre), v. 24, n. 2, p. 399-412, 2018. DOI: https://doi. org/10.22456/1982-8918.65543

MURAD, Maurício. Sociologia e Educação Física: diálogos, linguagens do corpo, esportes. Rio de Janeiro: Fundação Getúlio Vargas, 2009.

PAULA, Sayonara Cunha de et al. Avaliação educacional: currículos de formação de professores em educação física na América Latina. Revista Brasileira de Ciências do Esporte, v. 42, 2020. DOI: https://doi.org/10.1016/j.rbce.2018.09.005.

PELLEGRINI, Ana Maria. A formação profissional em educação física. In: PASSOS, S.(org.). Educação Física e esportes na universidade. Brasília: Ministério da Educação, Secretaria de Educação Física e Desportos, 1988. p. 247-259.

SALVIATI, Maria Elizabeth (comp.). Manual do aplicativo Iramuteq: compilação, organização e notas. Planaltina, DF, 2017.

SANTOS, Wagner dos et al. Da relação com o saber às identidades da EF: narrativas de estudantes do Ensino Médio. Pro-Posições, v. 31, 2020. DOI: https://doi.org/10.1590/1980$\underline{6248-2019-0074 .}$.

SILVA, Isabelli Fiorelli. O sistema nacional de avaliação: características, dispositivos legais e resultados. Estudos em Avaliação Educacional, v. 21, n. 47, p. 427-448, set./dez. 2010.

SILVEIRA, Fernando Lang da; BARBOSA, Marcia Cristina Bernardes; SILVA, Roberto da. Exame Nacional do Ensino Médio (ENEM): uma análise crítica. Revista Brasileira de Ensino de Física, v. 37, n. 1, p. 1101, 2015.

SO, Marcos Roberto; BETTI, Mauro. Saber ou fazer? O ensino de lutas na Educação Física escolar. COLÓQUIO DE PESQUISA QUALITATIVA EM MOTRICIDADE HUMANA: AS LUTAS NO CONTEXTO DA MOTRICIDADE HUMANA, 4. São Carlos-SP: Sociedade de Pesquisa Qualitativa em Motricidade Humana/UFSCar, Anais... 2009. p. 540-553,

STRAZZACAPPA, Márcia. O swing do ensino de dança no Brasil: um balanço de quase duas décadas. Dança: Revista do Programa de Pós-Graduação em Dança, v. 3, n. 1, p. 1-15, 2014.

SUDBRACK, Edite Maria; COCCO, Eliane Maria. Avaliação em larga escala no Brasil: potencial indutor de qualidade? Roteiro, v. 39, n. 2, p. 347-370, jul./dez. 2014.

VIANNA, Heraldo Marelim. Avaliações nacionais em larga escala: análises e propostas. Estudos em Avaliação Educacional, v. 25, n. 60, p. 196-232, 2014. 
Abstract: The article analyzes the new Enem questions that contain Physical Education knowledge objects, understanding the relationships established by and between knowledge areas mediated by competences and abilities. Being qualitative in nature, it employs document-critical analysis as its methodology. Sources include: 49 questions related to Physical Education in the examination (2009 to 2017), the National Guidelines for Secondary Education, the Basic Enem Document, and the Enem Reference Matrix. Uses and appropriations of Physical Education contents, due to their multidisciplinary nature, favors examination's questions focused on interdisciplinarity by and between knowledge areas, exploring subjects' daily relationships. Interaction between the objectives of the "Languages and their Technologies" area, promoted by the examination, allows us to understand Physical Education within a broad context of training, in addition to domain knowledge.

Keywords: Examination questions. Physical Education. Education, primary and secondary. Qualitative research.

Resumen: El estudio analiza las preguntas del Nuevo Enem (Examen Nacional de la Enseñanza Media) que presentan objetos de conocimiento de la Educación Física, abarcando las relaciones que se establecen por y entre las áreas de conocimiento mediadas por competencias y habilidades. De naturaleza cualitativa, utiliza el análisis crítico-documental como metodología. Las fuentes están compuestas por: 49 preguntas relacionadas con la Educación Física en el examen (2009 a 2017), las Directrices Nacionales para la Enseñanza Media, el Documento Básico del Enem y la Matriz de Referencia del Enem. Los usos y apropiaciones de los objetos de conocimiento de la Educación Física, por su carácter multidisciplinario, favorecen la exigencia de elaborar las preguntas del examen buscando la interdisciplinariedad por y entre las áreas de conocimiento, explorando las relaciones cotidianas de los sujetos. La interacción entre los objetivos del área de Lenguas y sus Tecnologías, impulsada por el examen, nos permite comprender la Educación Física dentro de un amplio contexto de formación, más allá de los saberes del campo.

Palabras clave: Preguntas de examen. Educación Física. Enseñanza primaria y secundaria. Investigación cualitativa. 


\section{LICENÇA DE USO}

Este é um artigo publicado em acesso aberto (Open Access) sob a licença Creative Commons Atribuição 4.0 Internacional (CC BY 4.0), que permite uso, distribuição e reprodução em qualquer meio, desde que o trabalho original seja corretamente citado. Mais informações em: https://creativecommons.org/licenses/by/4.0

\section{CONFLITO DE INTERESSES}

Os autores declararam que não existe nenhum conflito de interesses neste trabalho.

\section{CONTRIBUIÇÕES AUTORAIS}

Rodrigo Marques: conceituação, curadoria de dados, análise formal, investigação, metodologia, redação, revisão e edição.

Jean Carlos Freitas Gama: conceituação, curadoria de dados, análise formal, investigação, metodologia, redação, revisão e edição.

Geraldo Luzia Oliveira Junior: curadoria de dados, análise formal, investigação, metodologia, redação.

Amarílio Ferreira Neto: conceituação, análise formal, investigação, supervisão, redação e revisão.

Wagner dos Santos: conceituação, análise formal, investigação, supervisão, redação, revisão e edição.

\section{FINANCIAMENTO}

O presente trabalho foi realizado com apoio da Fundação de Amparo à Pesquisa do Espírito Santo (Fapes) com concessão de bolsa. Também contou com financiamento do Conselho Nacional de Desenvolvimento Científico e Tecnológico (CNPq), sob o Edital MCTIC/CNPq No 28/2018 - Universal/Faixa B, No do processo: 435310/20186.

\section{COMO REFERENCIAR}

MARQUES. Rodrigo; GAMA, Jean Carlos Freitas; OLIVEIRA JUNIOR, Geraldo Luzia; FERREIRA NETO, Amarílio; SANTOS, Wagner dos. Educação física no Ensino Médio e os exames estandardizados: uma análise das questões no novo ENEM. Movimento (Porto Alegre), v.27, p.e27076, jan./dez. 2021. Disponível em: https://seer.ufrgs.br/Movimento/article/view/113585. Acesso em: [dia] [mês abreviado]. [ano]. DOI: https://doi.org/10.22456/1982-8918.113585

\section{RESPONSABILIDADE EDITORIAL}

Alex Branco Fraga*, Elisandro Schultz Wittizorecki*, Ivone Job*, Mauro Myskiw*, Raquel da Silveira*

*Universidade Federal do Rio Grande do Sul, Escola de Educação Física, Fisioterapia e Dança, Porto Alegre, RS, Brasil. 